MENDONÇA, C. D. de et al. Interferência da adição da biomassa e farinha de banana verde (Musa spp.) e farinha da casca de jabuticaba (Myrciaria cauliflora) na multiplicação de bactérias probióticas em leite cultivado light

\title{
INTERFERÊNCIA DA ADIÇÃO DE BIOMASSA E FARINHA DE BANANA VERDE (Musa spp.) E FARINHA DA CASCA DE JABUTICABA (Myrciaria cauliflora) NA MULTIPLICAÇÃO DE BACTÉRIAS PROBIÓTICAS EM LEITE CULTIVADO LIGHT ${ }^{l}$
}

\author{
Cristina Dias de Mendonça ${ }^{2}$ \\ Sueli Ciabotti ${ }^{3}$ \\ Maísa Lamounier Magalhães ${ }^{4}$ \\ Fernanda Gonçalves Carlos ${ }^{5}$ \\ Alessandra Regina Vital ${ }^{6}$
}

\section{RESUMO}

A demanda por alimentos que apresentam efeitos benéficos tem estimulado as indústrias a desenvolverem produtos funcionais. Nesse contexto, objetivou-se no presente estudo, avaliar a interferência da adição de biomassa, farinha de banana verde, e de farinha da casca de jabuticaba na manutenção de cultura probiótica em leites cultivados light. Foram elaboradas 4 formulações designadas por F1 (controle), F2 (10\% biomassa), F3 (5\% de farinha de banana) e F4 (5\% de polpa de jabuticaba e $0,8 \%$ de farinha da casca de jabuticaba). As amostras foram submetidas à contagem de bactérias lácticas totais nos tempos $0,10,20$ e 30 dias. Foi utilizada cultura probiótica mista de Lactobacillus acidophilus, Bifidobacterium sp. e Streptococcus salivarius subsp. thermophillus. A contagem de bactérias lácticas totais atendeu às exigências da legislação e a adição de biomassa, farinha de banana verde e farinha da casca de jabuticaba influenciaram na viabilidade da cultura probiótica durante o período de estocagem.

Palavra-chave: Leite fermentado. Alimento funcional. Fibra alimentar.

\footnotetext{
${ }^{1}$ Como citar este artigo:

MENDONÇA, C. D. de et al. Interferência da adição da biomassa e farinha de banana verde (Musa spp.) e farinha da casca de jabuticaba (Myrciaria cauliflora) na multiplicação de bactérias probióticas em leite cultivado light. ForScience: revista científica do IFMG, Formiga, v. 5, n. 2, e00321, out. 2017. Edição especial.

${ }^{2}$ Mestrado em Ciência e Tecnologia de Alimentos pelo Instituto Federal de Educação, Ciência e Tecnologia pelo Triângulo Mineiro (IFTM) - Campus Uberaba. Atualmente Técnica em Alimentos e Laticínios no Instituto Federal de Educação, Ciência e Tecnologia de Minas Gerais (IFMG) - Campus Bambuí. Lattes: http://lattes.cnpq.br/3117344899250222 E-mail: cristina.mendonca@ifmg.edu.br

${ }^{3}$ Doutorado em Ciência dos Alimentos pela Universidade Federal de Lavras (UFLA). Professora do IFTMCampus Uberaba - MG. Currículo Lattes: http://lattes.cnpq.br/9238124364416544. E-mail: sueliciabotti@iftm.edu.br

${ }^{4}$ Mestrado em Ciência e Tecnologia de Alimentos pelo IFTM - Campus Uberaba - MG. Currículo Lattes: http://lattes.cnpq.br/2554427068862027. E-mail: maisalamounier@yahoo.com.br.

${ }^{5}$ Especialização em Controle de Qualidade na Indústria de Alimentos pelo (IFMG) - Campus Bambuí - MG. Currículo Lattes: http://lattes.cnpq.br/9321970860225185. E-mail: fernanda.gvc@ifmg.edu.br.

${ }^{6}$ Mestranda em Ciência e Tecnologia de Alimentos pelo IFTM - Campus Uberaba - MG. Currículo Lattes: http://lattes.cnpq.br/3456827846186219. E-mail:alessandra.vital@ifmg.edu.br.
} 


\section{INTRODUÇÃO}

Um dos métodos mais antigos utilizados para conservação do leite é a produção de leites fermentados. No entanto, a fermentação deixou de ser utilizada apenas como método de conservação, transformando-se em uma forma de diversificar a gama de produtos lácteos (PRUDÊNCIO, 2005; ZICKER, 2011).

A demanda do mercado consumidor por alimentos saudáveis e que possam contribuir à prevenção de doenças tem incentivado a indústria de alimentos a desenvolver produtos funcionais. Os lácteos fermentados que apresentam microrganismos probióticos tem conquistado grande popularidade entre o público que busca por alimentos funcionais (GALLINA, 2010). No mercado, o segmento de alimentos probióticos foi dominado pelos produtos lácteos, uma vez que os consumidores estão familiarizados com o fato de que os leites fermentados apresentam em sua composição microrganismos viáveis, reconhecidos como benéficos à saúde (LEITE, 2015).

O consumo de leites fermentados no Brasil é baixo, quando comparado a outros países como França, Uruguai e Argentina. Uma alternativa viável ao consumo de leite fermentado pode ser a utilização de novos ingredientes que atendam às expectativas dos consumidores (GIESE et al., 2010). Nos últimos anos a fabricação de leites fermentados no Brasil cresceu de maneira considerável, e está em plena expansão. A produção de leite fermentado que apresente alegações funcionais vem crescendo de forma exponencial, ocupando importante fatia do mercado. Observa-se ainda a procura dos consumidores por alimentos com alegação funcional. Esse comportamento se reflete na procura por alimentos que, preferencialmente, possuam efeitos fisiológicos e benefícios à saúde. Os lácteos funcionais estão entre os alimentos mais vendidos, contribuindo com $73 \%$ do total de vendas (LOPES, 2010).

Entre os constituintes químicos com alegação funcional destacam-se os antioxidantes, presentes em alimentos vegetais, principalmente aqueles que apresentam coloração escura, compostos fenólicos, fibras, amido resistente, probióticos e prebióticos (ÂNGELO; JORGE, 2007; BEZERRA, 2010; VIEIRA et al., 2011). Dentre os alimentos funcionais, destacam-se aqueles que vinculam probióticos.

Estudos comprovam que as bactérias probióticas crescem lentamente no leite em função da falta de atividade proteolítica não desenvolvendo características reológicas e sensoriais acentuadas. A adição de substâncias prebióticas a microrganismos probióticos é uma estratégia para melhorar o crescimento dos probióticos durante a fermentação e aumentar a viabilidade durante o período de armazenamento (DAMIN et al., 2008). A interação entre 
probiótico e prebiótico em produtos lácteos, em geral é favorecida pela adaptação do probiótico ao substrato prebiótico, o que acarreta uma vantagem competitiva de multiplicação para o probiótico (SAAD, 2006). Assim, a adição de fibras e amido resistente propicia aumento de disponibilidade de nutrientes que atuam como substrato ao crescimento e manutenção da cultura probiótica (MONTANUCI; GARCIA; PRUDENCIO, 2010).

A casca da jabuticaba (Myrciaria cauliflora) atualmente é fonte de estudos relacionados à presença de compostos fenólicos, que atuam como antioxidantes. A utilização da casca e semente de jabuticaba torna-se interessante, uma vez que são considerados resíduos e representam aproximadamente $50 \%$ da fruta e, se aproveitadas na elaboração de alimentos podem agregar-lhes maior valor (ARAÚJO, 2011). Outra fonte de estudos é a banana (Musa spp.) verde que está entre a grande variedade de alimentos que possui benefícios comprovados à saúde humana (ZANDONADI, 2009; IBGE, 2011). De acordo com sua constituição, o amido resistente, presente em grande quantidade na banana verde, pode ser considerado um alimento funcional, pois está associado à prevenção de doenças crônicas como o câncer, diabetes, dislipidemias, doenças coronárias e obesidade (PERUCHA, 2005; BIANCHI, 2010).

Considerando a tendência à elaboração de leites cultivados funcionais e a possibilidade de produção de formulações com adição de fibra e amido resistente como ingredientes prebióticos, esse estudo foi desenvolvido para verificar a viabilidade tecnológica do aproveitamento da polpa e casca de jabuticaba e da banana verde nas formas de biomassa e farinha, apresentando-se como alternativa ao crescimento e viabilidade da cultura probiótica em leite cultivado.

\section{DESENVOLVIMENTO}

\subsection{Leites Fermentados ou Cultivados}

De acordo com a legislação brasileira, entende-se por leite fermentado ou cultivado os produtos adicionados ou não de outras substâncias alimentícias, obtido por coagulação e diminuição do $\mathrm{pH}$ do leite, ou leite reconstituído, adicionado ou não de outros produtos lácteos, por fermentação láctica mediante ação de cultivos de microrganismos específicos, que de acordo com sua atividade, contribuem para a determinação das características do produto final. Esses microrganismos devem ser ativos, viáveis e abundantes no produto final durante todo o período de armazenamento (BRASIL, 2007). 
Os leites fermentados, do ponto de vista econômico, são os derivados dos lácteos que apresentam melhores margens de rentabilidade, o que pode ser justificado pelo fato de não passarem por nenhum processo de concentração. Esse segmento corresponde a $80 \%$ do mercado de refrigerados, sendo $8 \%$ correspondente aos leites fermentados com propriedades funcionais (GALLINA, 2010). O mercado de leites fermentados está em plena expansão impulsionado pelo crescente desejo dos consumidores por produtos mais saudáveis e nutritivos ou, ainda, que apresentem baixo valor calórico (RIBEIRO et al., 2010; GALLINA et al., 2011).

\subsection{Alimentos Funcionais}

A preocupação da população com a qualidade de vida, principalmente no que se refere à saúde, tem dado destaque aos alimentos chamados funcionais. O termo "alimento funcional" foi introduzido pelo Japão na década de 1980 e uma das definições mais completas descreveos como sendo aqueles que ao serem consumidos, além das funções nutricionais, beneficiem uma ou mais funções orgânicas, além da nutrição básica, contribuindo para melhorar o estado de saúde e bem-estar e/ou reduzir o risco de doenças (MORAES, 2007). Para que os alimentos funcionais sejam eficazes é preciso que o consumo seja regular (VIDAL et al., 2012).

De acordo com a legislação brasileira, o alimento ou ingrediente que alegar propriedades funcionais ou de saúde deve produzir, além de funções nutricionais básicas, efeitos metabólicos e fisiológicos benéficos à saúde, devendo ser seguro para consumo sem supervisão médica (BRASIL, 1999).

A Agência Nacional de Vigilância Sanitária (ANVISA), em sua lista de alimentos funcionais, atualizada em julho de 2008, decretou como requisito para alegação de alimento funcional contendo probióticos que estes devem estar presentes no leite cultivado, na porção diária de $200 \mathrm{~mL}$, na faixa de $10^{8}$ a $10^{9} \mathrm{UFC} / \mathrm{g}$ ou mL (BRASIL, 2008).

\subsection{Probióticos}

A palavra "probiótico" deriva do grego e significa "para a vida". O interesse por microrganismos potencialmente benéficos à saúde é de tempos remotos. A definição mais comumente utilizada para probióticos é de suplementos alimentares contendo microrganismos vivos, os quais afetam de forma benéfica a saúde do hospedeiro mediante melhoria do balanço 
da flora microbiana intestinal de indivíduos que consumam periodicamente esses produtos, contribuindo para melhorar o equilíbrio microbiano intestinal (BRASIL, 2002).

Os probióticos apresentam capacidade para resistir ao suco gástrico ácido produzido no estômago, aos sais biliares e às enzimas digestivas, possuem capacidade de aderir à mucosa intestinal, conviver com a microbiota intestinal endógena e produzir substâncias que inibem o crescimento de bactérias indesejáveis. Os prebióticos podem ser uma importante alternativa à potencialização dos efeitos dos probióticos, uma vez que quando adicionados aos produtos alimentícios favorecem a multiplicação dos microrganismos probióticos no cólon do intestino, por servirem como substratos para o desenvolvimento destas culturas (ALVES; SANTOS; BECKER, 2009). Para assegurar benefícios à saúde do consumidor, a cultura probiótica deve permanecer viável durante todo o período de armazenamento (DONKOR et al., 2006).

\subsection{Fibra Alimentar}

Durante muito tempo a fibra foi considerada a porção inerte do alimento, no entanto, nas últimas décadas o interesse pelas fibras alimentares aumentou consideravelmente (EUFRÁSIO et al., 2009). As fibras são componentes de plantas ou carboidratos análogos que resistem à digestão e absorção no intestino delgado humano. Uma dieta rica em fibras contribui à manutenção da saúde, redução de riscos e tratamento de várias doenças. Atualmente entre os alimentos enriquecidos com fibras, os prebióticos têm ocupado lugar de destaque, esses são componentes alimentares não digeríveis. Quando consumidos regularmente, os prebióticos podem inibir a multiplicação de patógenos, propiciando efeitos benéficos à saúde (SAAD, 2006).

Por ser considerada o principal componente de vegetais, frutas e cereais integrais, a fibra alimentar permitiu que esses alimentos pudessem ser incluídos na categoria dos alimentos funcionais. Sua utilização, dentro de uma dieta balanceada, pode reduzir o risco de algumas doenças, além de agregar uma série de benefícios (ZANDONADI, 2009).

\subsection{Prebióticos}

O alimento classificado como prebiótico é aquele que não sofre hidrólise e não é absorvido na parte superior do trato gastrointestinal. É um substrato seletivo para um número limitado de bactérias potencialmente benéficas do cólon, que são estimuladas para crescerem e desenvolverem atividades metabólicas. O prebiótico deve ser capaz de promover uma biota 
intestinal saudável e como consequência, induzir efeitos no lúmen que beneficiem o hospedeiro (GALLAND, 2013).

Quando um prebiótico é adicionado a um probiótico, a atividade probiótica aumenta significativamente. A adição de amido resistente proveniente de banana verde apresenta-se como alternativa à interação entre probiótico e prebiótico, promovendo uma vantagem competitiva para o probiótico se este for consumido juntamente com o prebiótico (CHONG; NOOR, 2010).

\subsection{Bactérias lácticas}

O grupo de bactérias lácticas, bactérias do ácido láctico, é um dos grupos que apresentam maior importância para o homem, tanto pelo papel que exerce na produção e prevenção dos alimentos quanto pelo envolvimento em diferentes aspectos da saúde humana. A aplicação de bactérias lácticas probióticas exige o conhecimento dos fenótipos responsáveis por sua funcionalidade e, consequentemente de sua aplicação tecnológica (FERREIRA, 2012).

O emprego de bactérias probióticas em produtos lácteos fermentados tem sido amplamente estudado devido às dificuldades de manutenção da viabilidade destes microrganismos ao longo da estocagem refrigerada. Fatores como acidez, oxigênio dissolvido, interações entre espécies, práticas de inoculação e condições de estocagem podem influenciar na sobrevivência da microbiota probiótica em produtos lácteos fermentados. As bactérias empregadas com maior frequência comercialmente como probióticas para alimentos são dos gêneros Lactobacillus e Bifidobacterium (KOLIDA; GIBSON, 2011).

\subsection{Banana}

O Brasil é um dos maiores produtores mundiais de banana, em 2011 a produção foi de 7. 329,471 toneladas. As principais regiões produtoras foram Nordeste, Sudeste e Sul (IBGE, 2011). No Brasil, a banana é cultivada em todos os estados, os maiores estados nacionais produtores de banana são Bahia, São Paulo, Santa Catarina, Pernambuco e Minas Gerais respectivamente (OLIVEIRA, 2010).

A utilização da banana no estágio de maturação ainda verde apresenta-se como uma alternativa de minimizar as perdas pós-colheita, que chegam a $60 \%$ da produção nacional. Um dos principais constituintes da banana verde é o amido, sendo boa parte, considerado amido 
resistente. $\mathrm{O}$ amido resistente presente na banana verde tem despertado o interesse de pesquisadores de diversas áreas, por propriedades nutricionais benéficas à saúde dos indivíduos que o consome (ALMEIDA, 2013). Esse amido apresenta comportamento similar ao da fibra alimentar, estando relacionada a efeitos benéficos locais e sistêmicos, através de uma série de mecanismos (BIANCHI, 2010). O amido resistente mostra-se como uma das fibras mais eficazes e dessa forma, apresenta-se como aliado às pessoas que pretendem manter o peso saudável e prevenir a obesidade (PERUCHA, 2005).

\subsection{Jabuticaba}

Pertencente à família Myrtaceae, nativa do Brasil a jabuticabeira é uma árvore frutífera originária do centro-sul. Conhecido popularmente como jabuticaba, o fruto de Myrciaria cauliflora é caracterizado como baga globosa de até $3 \mathrm{~cm}$ de diâmetro, com casca pretoavermelhada, polpa esbranquiçada, mucilaginosa, agridoce, sub-ácida, apresentando de uma a quatro sementes (ARAÚJO, 2011).

Em função de sua grande aceitação, o estímulo à produção de alimentos com utilização desse fruto tem aumentado consideravelmente. No Brasil, seu consumo aumenta a cada ano. A jabuticaba não apresenta grande valor comercial e a comercialização é prejudicada por ser bastante perecível. A utilização industrial é limitada em função de sua alta perecibilidade, dificuldade de transporte e armazenamento. A jabuticaba apresenta considerável porcentagem de compostos fenólicos em sua composição, principalmente na casca. Portanto, a utilização desse resíduo na elaboração de subprodutos torna-se uma alternativa ao enriquecer de alimentos tais como o leite fermentado (SANTOS; VEGGI; MEIRELES, 2010).

\subsection{Materiais e métodos}

Foram utilizados no desenvolvimento dos leites cultivados, leite bovino padronizado a $1 \%$ de gordura de acordo com a legislação vigente (BRASIL, 2011) e banana (Musa spp.) da cultivar nanica, verde provenientes dos setores de bovinocultura e agricultura I, respectivamente, cedidos pelo Instituto Federal de Educação Ciência e Tecnologia de Minas Gerais - Campus Bambuí (IFMG), para a obtenção da biomassa, da farinha e dos leites cultivados. As Jabuticabas (Myrciaria cauliflora) da variedade sabará foram colhidas na cidade de Bambuí - MG, e a cultura lática termofílica, liofilizada, de cepas mistas: Lactobacillus acidophilus, Bifidobacterium sp. e Streptococcus salivarius subsp. 
thermophillus (DVS ABT 4 - 50U, CHR. HANSEN®), foi adquirida em comércio especializado.

A produção das formulações de leite cultivado seguiu a metodologia descrita por Tamine e Robinson (1991). A contagem de bactérias lácticas totais foi realizada no laboratório de microbiologia do Departamento de Ciências Agrárias, do Instituto Federal de Educação Ciência e Tecnologia de Minas Gerais - Campus Bambuí (IFMG). Foi estabelecido como período de armazenamento 30 dias à $4^{\circ} \mathrm{C}$, em que as formulações foram avaliadas nos tempos $0,10,20$ e 30 dias, quanto à contagem de bactérias lácticas totais.

\subsubsection{Contagem de bactérias lácticas totais}

Para a enumeração de bactérias ácido lácticas totais foi utilizado o meio MRS com glicose e adicionado de solução de dicloxacilina (solução A), cloridrato de cisteína (solução B) e cloreto de lítio (solução C). Uma alíquota de $10 \mathrm{~g}$ de amostra foi transferida para um tubo com rosca contendo $90 \mathrm{~mL}$ de solução de água peptonada estéril $0,1 \%$. A partir dessa diluição foram feitas diluições subsequentes, necessárias à análise do produto. Foi empregada a técnica de plaqueamento em profundidade. As placas de Petri foram incubadas invertidas a $37^{\circ} \mathrm{C}$ por 72 horas (THARMARAJ; SHAH, 2003). Para melhoria das condições de multiplicação foi adicionado uma sobrecamada de agar, após o tempo de incubação a contagem foi realizada nas placas que apresentaram entre 25 e 250 colônias (SILVA et al., 2010).

\subsubsection{Análise estatística}

Para a variável contagem de bactérias lácticas totais realizadas durante $\mathrm{o}$ armazenamento, utilizou-se um delineamento inteiramente casualizado (DIC) com 4 tratamentos e 3 repetições, em experimento fatorial 4 x 4 , no fator principal estão os tratamentos: F1, controle, sem adição de jabuticaba e sem banana verde, F2, leite cultivado com adição de $10 \%$ de biomassa de banana verde, F3, leite cultivado com adição de $5 \%$ de farinha de banana verde e F4, leite cultivado com adição de $5 \%$ de polpa de jabuticaba e 0,8 $\%$ de farinha da casca de jabuticaba, versus os tempos de armazenamento refrigerado que foram 0, 10, 20 e 30 dias após a fabricação.

Para identificar as diferenças significativas, os dados foram submetidos à análise de variância (ANOVA), teste de comparação de médias de Tukey $(p<0,05)$ e regressão. Os dados 
foram analisados segundo técnicas usuais do software SISVAR $(\mathrm{p}<0,05)$ (FERREIRA, D. 2007).

\section{RESULTADO E DISCUSSÃO}

\subsection{Contagem de bactérias lácticas totais}

Os resultados da contagem de bactérias lácticas totais, nas formulações de leite cultivado padrão, e nas formulações adicionadas de biomassa de banana verde, farinha de banana verde e jabuticaba estão apresentados na Tabela 1.

Tabela 1- Dados médios da contagem em unidade formadora de colônias por $\mathrm{mL}$ (UFC/mL) de bactérias lácticas totais, viáveis nos leites cultivados em diferentes tempos de armazenamento

\begin{tabular}{lllll}
\hline \multirow{2}{*}{ Leites cultivados } & \multicolumn{4}{c}{$\begin{array}{c}\text { UFC/mL de Bactérias Ácido Lácticas } \\
\text { Tempo }^{1} \text { (dias) }\end{array}$} \\
\cline { 2 - 5 } & 0 & 10 & 20 & 30 \\
\hline F1 & $1,25 \times 10^{7 \mathrm{c}}$ & $1,23 \times 10^{7 \mathrm{a}}$ & $1,17 \times 10^{7 \mathrm{~d}}$ & $1,11 \times 10^{7 \mathrm{c}}$ \\
F2 & $1,66 \times 10^{7 \mathrm{~b}}$ & $1,23 \times 10^{7 \mathrm{a}}$ & $1,49 \times 10^{7 \mathrm{c}}$ & $1,51 \times 10^{7 \mathrm{~b}}$ \\
F3 & $2,10 \times 10^{7 \mathrm{a}}$ & $1,23 \times 10^{7 \mathrm{a}}$ & $1,66 \times 10^{7 \mathrm{~b}}$ & $2,29 \times 10^{7 \mathrm{a}}$ \\
F4 & $2,13 \times 10^{7 \mathrm{a}}$ & $1,28 \times 10^{7 \mathrm{a}}$ & $2,84 \times 10^{7 \mathrm{a}}$ & $1,47 \times 10^{7 \mathrm{~b}}$ \\
\hline $\mathrm{CV}(\%)$ & \multicolumn{4}{c}{5,31}
\end{tabular}

${ }^{1}$ Médias seguidas de mesma letra na coluna não diferem entre si pelo teste de Tukey $(\mathrm{p}<0,05)$. Dados médios da contagem de bactérias lácticas totais viáveis nos leites cultivados F1 - (controle), F2 - (biomassa de banana verde), F3 - (farinha de banana verde), F4 - (jabuticaba) em diferentes tempos de armazenamento refrigerado.

A contagem de BAL variou de 1,25 a 2,13 x $10^{7} \mathrm{UFC} / \mathrm{mL}$ no primeiro dia e de 1,11 a 2,29 × $10^{7} \mathrm{UFC} / \mathrm{mL}$ no trigésimo dia de armazenamento. No tempo 0, os leites cultivados F3, com adição de farinha de banana verde e F4, com adição de jabuticaba apresentaram as maiores contagens, variando entre $2,10 \times 10^{7} \mathrm{UFC} / \mathrm{mL}$ e $2,13 \times 10^{7} \mathrm{UFC} / \mathrm{mL}$ respectivamente, não diferindo entre si $(p>0,05)$, e diferindo das demais formulações $(p<0,05)$. O leite cultivado F1, controle, obteve menor contagem $1,25 \times 10^{7} \mathrm{UFC} / \mathrm{mL}$ diferindo das demais formulações $(\mathrm{p}<0,05)$. O leite cultivado $\mathrm{F} 2$, com adição de biomassa apresentou contagem intermediária, diferindo das demais formulações $(\mathrm{p}<0,05)$ nesse tempo.

No tempo 10, não houve diferença significativa entre nenhuma das formulações de leites cultivados, no entanto, a formulação F4, com adição de jabuticaba atingiu maior contagem de bactérias lácticas totais $1,28 \times 10^{7} \mathrm{UFC} / \mathrm{mL}$, ficando as formulações $\mathrm{F} 1$, 
controle, F2, com adição de biomassa de banana verde e F3, com adição de farinha de banana verde com média $1,23 \times 10^{7} \mathrm{UFC} / \mathrm{mL}$.

No tempo 20, todas as formulações de leites cultivados diferiram entre $\operatorname{si}(\mathrm{p}<0,05)$. A formulação F4, com adição de jabuticaba obteve maior contagens de BAL, 2,84 x $10^{7}$ $\mathrm{UFC} / \mathrm{mL}$. As formulações F3, com adição de farinha de banana verde e F2, com adição de biomassa de banana verde obtiveram contagem intermediárias, ficando a formulação F1, controle com menor contagem de bactérias lácticas totais 1,17 x $10^{7} \mathrm{UFC} / \mathrm{mL}$.

Ao final do armazenamento refrigerado, no tempo 30, a contagem de bactérias lácticas totais variou entre 1,11 a 2,29 x $10^{7} \mathrm{UFC} / \mathrm{mL}$. O leite cultivado $\mathrm{F} 3$, com adição de farinha de banana verde atingiu maior contagem $2,29 \times 10^{7} \mathrm{UFC} / \mathrm{mL}$, diferindo das demais formulações $(\mathrm{p}<0,05)$. Os leites cultivados $\mathrm{F} 2$, com biomassa e $\mathrm{F} 4$, com jabuticaba não apresentaram diferença entre si $(\mathrm{p}>0,05)$, alcançando contagens intermediárias. $\mathrm{O}$ leite cultivado $\mathrm{F}$ 1, controle obteve menor contagem $1,11 \times 10^{7} \mathrm{UFC} / \mathrm{mL}$.

De acordo com Ferreira (2012), prebióticos são geralmente adicionados a leites fermentados para seletivamente estimular o crescimento e a manutenção de culturas probióticas. No estudo, a farinha da casca de jabuticaba, a biomassa de banana verde e a farinha de banana verde quando adicionadas às formulações podem ter aumentado a disponibilidade de nutrientes e favorecido a multiplicação das bactérias probióticas, uma vez que a amostra controle, sem adição de jabuticaba, biomassa de banana verde e farinha de banana verde, obteve menor contagem de bactérias lácticas do início ao final do armazenamento. O leite cultivado F3, com adição farinha de banana verde, alcançou maior contagem de bactérias lácticas totais no tempo $30 \mathrm{em}$ relação ao primeiro dia de armazenamento, o que pode ter ocorrido pela adição de farinha de banana verde que apresenta considerável teor de amido resistente em sua composição.

Observa-se através dos resultados obtidos que, as bactérias lácticas probióticas utilizadas mostraram-se viáveis até o trigésimo dia de armazenamento refrigerado, ficando todas as formulações com contagem de $10^{7} \mathrm{UFC} / \mathrm{mL}$, atendendo as exigências da Agência Nacional de Vigilância Sanitária (ANVISA), a qual preconiza que leites cultivados adicionados de culturas probióticas, deverão obter contagem entre $10^{6}$ a $10^{8} \mathrm{UFC} / \mathrm{mL}$ (BRASIL, 2007).

Diversas pesquisas evidenciam que a adição de ingredientes prebióticos mantém a viabilidade de bactérias lácticas durante a vida-de-prateleira do produto (GARCÍACAYUELA, 2014; SILVA; VIEIRA, 2014), o que pôde ser observado nesse trabalho. A contagem de bactérias lácticas totais alcançadas indica que houve maior sobrevivência nas 
formulações F3, com adição de farinha de banana verde, a qual apresenta maior percentual de amido resistente na formulação F4, com adição de jabuticaba que apresenta considerável teor de fibra. Os leites cultivados apresentaram contagem superior a $10^{6} \mathrm{UFC} / \mathrm{mL}$ durante todo o período de analisado.

O leite cultivado F3, com adição de farinha de banana verde do experimento mostrouse coerente com o estudo realizado por Nobhakti et al., (2009), que analisando a influência do amido resistente sobre a viabilidade dos microrganismos probióticos em leites fermentados simbióticos, observou que a maior viabilidade das bactérias lácticas totais foi obtida na formulação com 3\% de amido resistente. Vieira (2011) observou que o aumento da adição de amido resistente de 1,5 para 3,0\% influenciou a concentração de Bifidobacterium nos produtos durante todo o período de armazenamento, ressaltando ainda que a população de Bifidobacterium foi maior na formulação com maior concentração de amido resistente.

Os leites cultivados F3, com adição de farinha de banana verde, e F4, com adição de jabuticaba, reforçam a afirmação de que a adição com adição de jabuticaba e o leite cultivado com e fibra como prebióticos tendem a favorecer a sobrevivência dos microrganismos probióticos. Espírito Santo et al., (2010), observaram efeito positivo na utilização de polpa de açaí como prebiótico na viabilidade das bactérias lácticas totais em leite fermentado quando comparada à formulação sem adição de açaí. A contagem de bactérias lácticas totais, observada nos leites cultivados desse estudo, foi superior ao estudo de Leite (2015), em leite cultivado simbiótico de açaí com utilização de $10 \%$ de polpa, em que a contagem de bactérias lácticas totais foi $10^{5} \mathrm{UFC} / \mathrm{mL}$. Estudo realizado por Espírito Santo et al., (2012), indica que adição de farinhas de frutas como fonte de amido resistente e fibras melhora a viabilidade das bactérias probióticas. Pesquisa realizada com adição de $4 \%$ de farinha de lentilha ao leite fermentado mostrou ser capaz de aumentar a viabilidade das bactérias lácticas totais (AGIL et $a l, 2013)$.

Os resultados obtidos nos leites cultivados desse estudo foram superiores aos resultados de Pimentel, Garcia e Prudêncio (2012), adicionando 2\% de farinha de yacon e inulina como ingrediente prebiótico em leites fermentados probióticos, levando as bactérias lácticas totais mostrarem-se viáveis até $14^{\circ}$ dia de armazenamento. Borges et al., (2011), também afirmam que, analisando a viabilidade de Bifidobactérias em smoothie sabor goiaba com e sem adição de prebióticos, a contagem de bactérias lácticas, em todas as formulações se mantiveram constantes, tanto na amostra com inulina e frutooligossacarídeos quanto na amostra sem adição das fibras, evidenciando que nesse produto as fibras não influenciaram a manutenção dos probióticos. 
Souza (2015) utilizando 4\% de colostro bovino em pó em leites fermentados observou que a contagem de bactérias probióticas manteve-se em $10^{8} \mathrm{UFC} / \mathrm{mL}$ até o $30^{\circ}$ dia de armazenamento.

Os modelos linear e quadrático e o $\mathrm{R}^{2}$ ajustados aos dados experimentais da contagem de BAL totais (UFC/mL) em função da adição de jabuticaba, biomassa de banana verde e farinha de banana verde foram significativos $(\mathrm{p}<0,05)$ pela análise de variância e regressão e estão apresentados na Figura 01.

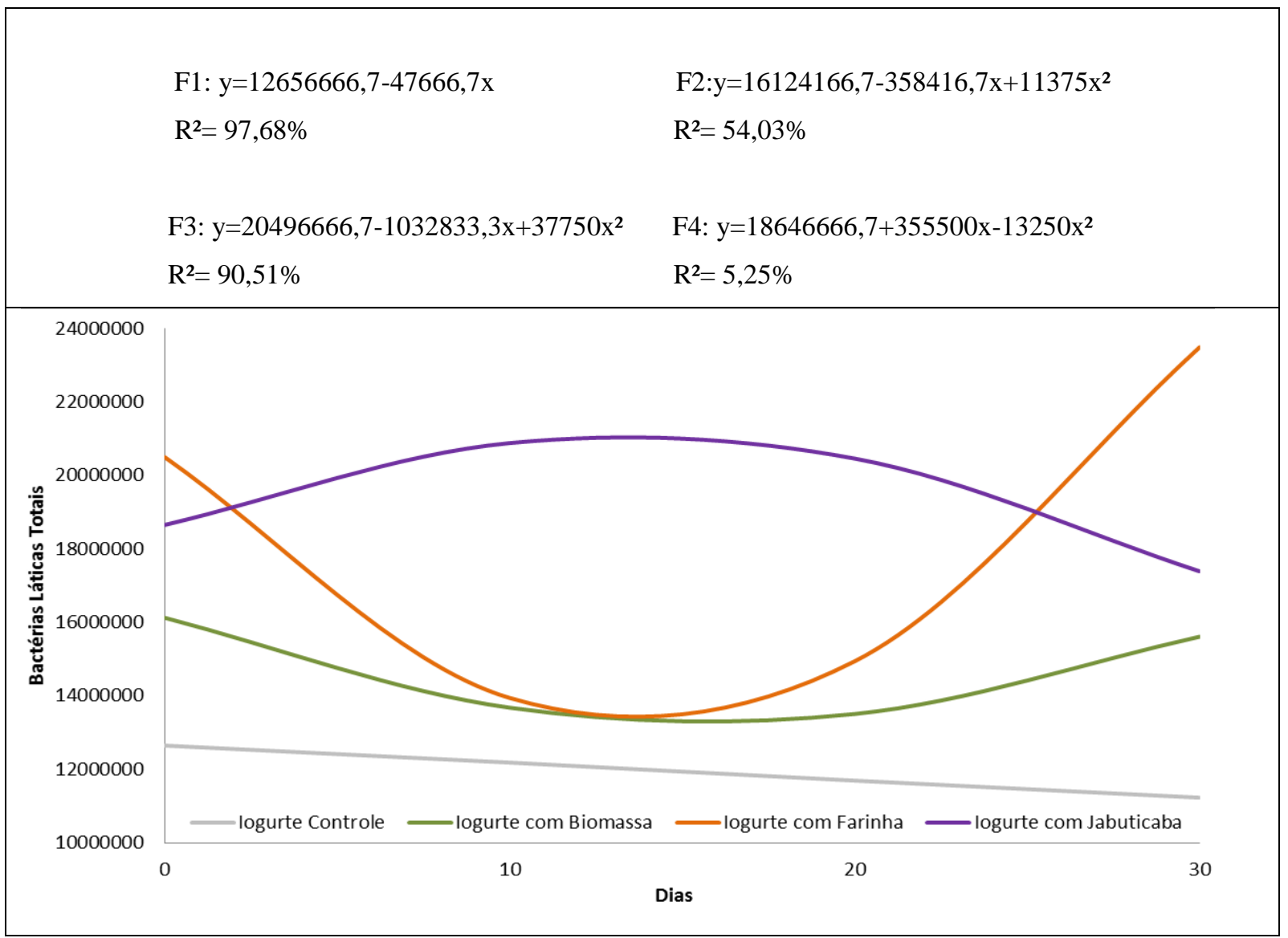

Figura 1- Modelo linear e modelo quadrático ajustados da contagem média de bactérias láticas totais (UFC/mL) em função do tempo de armazenamento (dias) dos leites cultivados. F1 - (controle), F2 - (biomassa de banana verde), F3 - (farinha de banana verde), F4 - (jabuticaba) em diferentes tempos de armazenamento refrigerado

As bactérias lácticas probióticas apresentaram efeito positivo em função do tempo de armazenamento, nas formulações de leite cultivado adicionados de jabuticaba, biomassa de banana verde e farinha de banana verde. Na formulação F1, houve um decréscimo linear do início ao final do armazenamento. Na formulação F2, com adição de biomassa de banana verde houve um decréscimo próximo ao décimo quinto dia, logo após houve um aumento até o final do armazenamento. Na formulação F3, com adição de farinha de banana verde, houve 
um decréscimo próximo do $14^{\circ}$ dia, em seguida, houve um aumento até o fim do armazenamento. A formulação de leite cultivado com jabuticaba F4, apresentou um aumento até o décimo quinto dia, seguido de redução do número de bactérias lácticas.

As formulações de leite cultivado F2, F3 e F4, adicionados de jabuticaba, biomassa de banana verde e farinha de banana verde respectivamente, apresentaram contagem de bactérias lácticas totais superiores à formulação controle, F1 em todos os tempos de armazenamento analisados. Esse resultado evidencia que tanto a farinha de jabuticaba, quanto a biomassa de banana verde e a farinha de banana verde influenciaram na manutenção da cultura probiótica, mostrando-se coerente com diversos estudos, em que vários autores afirmam que a adição de prebióticos preserva a viabilidade de bactérias láticas durante a vida de prateleira do produto (PAQUIN, 2009; TRENTO et al., 2009; ESPÍRITO SANTO et al., 2010; GALLINA et al., 2011; BORGES et al., 2011; CASAROTTI, 2013; LEITE, 2015).

Vários fatores influenciam a sobrevivência das bactérias probióticas em produtos lácteos, tais como acidez, cultura utilizada, quantidade inoculada, temperatura de incubação, temperatura de armazenamento, disponibilidade de nutrientes, interação entre as espécies presentes, conteúdo de sólidos do leite e oxigênio dissolvido, principalmente para as bifidobactérias que são anaeróbias. A pós-acidificação do leite fermentado, que ocorre durante o armazenamento resulta na produção de ácidos orgânicos através da atividade metabólica das bactérias lácticas tradicionais, com decréscimo do $\mathrm{pH}$ e aumento da acidez (DONKOR et al., 2006), esse fator leva à redução de bactérias probióticas viáveis, principalmente as bifidobactérias, que são pouco tolerantes ao ácido e apresentam multiplicação diminuída em pH menor que 5,0 o que reduz a vida de prateleira do produto (THAMER; PENNA, 2006; LEITE, 2015).

Ao final desse estudo, no entanto, foi observado que mesmo em meio que seria desfavorável à viabilidade das bactérias lácticas probióticas em função da elevação da acidez titulável (SAAD; CRUZ; FARIA 2011), houve multiplicação e essas mantiveram-se viáveis até o final do armazenamento, o que pode ter ocorrido em função da presença dos nutrientes como as fibras e amido resistente adicionados às formulações de leite cultivado.

\section{CONCLUSÃO}

Através desse estudo foi possível concluir que a adição de biomassa de banana verde, farinha de banana verde e jabuticaba aos leites cultivados proporcionaram aumento no crescimento e manutenção das bactérias lácticas totais durante todo o período de 
armazenamento. E ainda, uma vez comprovado a melhoria de aspectos inerentes aos valores da farinha de jabuticaba, da biomassa e da farinha da banana verde, tornam-se fundamentais novos estudos do aproveitamento desses alimentos produzidos no Brasil em larga escala, e que visem minimizar resíduos alimentares.

\section{REFERÊNCIAS}

AGIL, R. et al. Lentils enhance probiotic growth in yogurt and provide added benefit of antioxidant protection. LWT - Food Science and Technology, v. 50, n. 1, p. 45-49, 2013.

ALMEIDA, M. C. B. de M. Estudo para fins industriais das propriedades funcionais do amido nativo e modificado hidrotermicamente, provenientes da banana verde, variedade "prata". 2013. Dissertação (Mestrado em Sistemas Agroindustriais) Universidade Federal de Campina Grande, Pombal - Paraíba, 2013.

ALVES, L. L.; SANTOS, N. S. P.; BECKER, L. V. Aceitação sensorial e caracterização de frozen yogurt de leite de cabra com adição de cultura probiótica e prebiótico. Ciência Rural, v. 1, n. 1, p. 2-3, 2009.

ÂNGELO, P. M.; JORGE, N. Compostos fenólicos em alimentos: uma breve revisão. Revista Instituto Adolfo Lutz, v. 66, n. 1, p. 232-240, 2007.

ARAÚJO, C. R. R. Composição química, potencial oxidante e hipolipidêmico da farinha da casca de Myrciaria cauliflora (jabuticaba). Diamantina, 2011. 119 f. Dissertação (Mestrado em Química Orgânica) - Universidade Federal dos Vales do Jequitinhonha e Mucuri, Diamantina - Minas Gerais, 2011.

BEZERRA, K. C. Caracterização físico-química, reológica e sensorial de iogurte obtido pela mistura dos leites bubalino e caprino, 2010. Dissertação (Mestrado em Engenharia Química) - Universidade Federal do Rio Grande do Norte - Rio Grande do Norte, 2010.

BIANCHI, M. Benefícios da biomassa de banana verde na diminuição do risco de sobrepeso e/ou obesidade e suas comorbidades, 2010. Dissertação (Mestrado em Biociências e Nutrição) - Universidade Federal de São Paulo, São Paulo, 2010.

BORGES, B. et al. Desenvolvimento de bebida tipo "smoothie" simbiótica. In: CONGRESSO INTERNACIONAL DE INICIAÇÃO CIENTÍFICA (CIIC)., 5²011. Campinas. Anais... São Paulo: [s.n.], 9 a 11 de agosto, 2011.

BRASIL. Ministério da Saúde. Agência Nacional de Vigilância Sanitária. Portaria n. 398 de 30 de abril de 1999. Resolução n. 18 de 30 de abril de 1999. Aprova o Regulamento Técnico que Estabelece as Diretrizes Básicas para Análise e Comprovação de Propriedades Funcionais e ou de Saúde Alegadas em Rotulagem de Alimentos. Brasília, 1999. 
BRASIL. Agência Nacional de Vigilância Sanitária. Regulamento Técnico de Substâncias

Bioativas e Probióticos Isolados com Alegação de Propriedades Funcional ou de

Saúde, Resolução RDC n. 2, 7 de janeiro de 2002.

BRASIL. Ministério da Agricultura, Pecuária e Abastecimento (MAPA). Instrução

Normativa $n^{\circ}$ 46, de 23 de outubro de 2007. Adota o Regulamento Técnico de Identidade e Qualidade de Leites Fermentados, anexo à presente Instrução Normativa. Diário Oficial da União, Brasília, 24 de outubro de 2007.

BRASIL. Ministério da Saúde. Agência Nacional de Vigilância Sanitária. Alimentos com Alegações de Propriedades Funcionais e ou de Saúde, Novos Alimentos/Ingredientes, Substâncias Bioativas e Probióticos. IX - Lista de alegações de propriedade funcional aprovadas, 2008.

BRASIL. Ministério da Agricultura, Pecuária e Abastecimento (MAPA). Instrução Normativa $\mathbf{n}^{0}$ 62, de 29 de dezembro de 2011. Aprova o Regulamento Técnico de Produção, Identidade e Qualidade do Leite tipo A, o Regulamento Técnico de Identidade e Qualidade de Leite Cru Refrigerado, o Regulamento Técnico de Identidade e Qualidade de Leite Pasteurizado e o Regulamento Técnico da Coletade Leite Cru Refrigerado e seu Transporte a Granel, em conformidade com os Anexos desta Instrução Normativa. Diário Oficial da União, Brasília, 30 de dezembro de 2011.

CASAROTTI, S. N. Perfil tecnológico e funcional de cepas probióticas em leite fermentado, 2013. 174 f. Tese (Doutorado) - Universidade Estadual Paulista, São José do Rio Preto, 2013.

CHONG, L. C.; NOOR, A. A. Effects of banana flour and b-glucan on the nutritional and sensory evaluation of noodles. Food Chemistry, [S.1.], n. 119, 34-40, 2010.

DAMIN, M. R. et al. Effect of cold storage on culture viability and some rheological properties of fermented milk prepared with yogurt and probiotic bacteria. Journal of Texture Studies, v. 39, p. 40-45, 2008.

DONKOR, O. N. et al. Effect of acidification on the activity of probiotics in yoghurt during cols storage. Internacional Dairy Journal, v. 16, p. 1181-1189, 2006.

ESPÍRITO SANTO, A. P. D. et al. Açai pulp addition improves fatty acid profile and probiotic viability in yoghurt. International Dairy Journal, v. 20, n. 6, p. 415-422, 2010.

ESPÍRITO SANTO, A. P. et al. Fibers from fruit by-products enhance probiotic viability and fatty acid profile and increase CLA content in yoghurts. International Journal of Food Microbiology, v. 154, n. 3, p. 135-144, 2012.

EUFRÁSIO, M. R. et al. Efeito de diferentes tipos de fibras sobre frações lipídicas do sangue e fígado de ratos wistar. Ciênc. agrotec. v. 33 n. 6. Lavras, nov./dez. 2009. 
FERREIRA, C. L. de L. F. Prebióticos e probióticos: atualização e prospecção. Rio de Janeiro: Rúbio, 2012.

FERREIRA, L. C. Desenvolvimento de iogurtes probióticos e simbióticos sabor cajá (Spondias mombin L.). 2012, 93 f. Dissertação (Mestrado em Ciência e Tecnologia de Alimentos) - Universidade Federal de Pernambuco, Recife, 2012.

FERREIRA, D. F. SISVAR 5.0. sistema de análises estatísticas. Lavras: UFLA, 2007.

GALLAND, L. Functional Foods: health effects and clinical applications encyclopedia of human nutrition. 3. ed. [S.1: s.n.], p. 366-371, 2013.

GALliNA, D. A. et al. Caracterização de Leites Fermentados Com e Sem Adição de Probióticos e Prebióticos e Avaliação da Viabilidade de Bactérias Láticas e Probióticas Durante a Vida-de-Prateleira. UNOPAR Cient. Ciênc. Biol. Saúde, v. 13, n. 4, p.239-44, 2011.

GALLINA, D. A. Leites fermentados funcionais: tendências e inovações. Revista Ingredientes Tecnologia, n. 9, p. 26-30, 2010.

GARCÍA-CAYUELA. Selective fermentation of potential prebiotic lactose-derived oligosaccharides by probiotic bacteria. International Dairy Journal, v. 38, n. 1, p. 11-15, 2014.

GIESE, S. et al. Caracterização físico-química e sensorial de iogurtes comercializados na região oeste do Paraná. Revista Varia Scientia Agrárias, v. 01, n. 01, p. 121-129, 2010.

INSTITUTO BRASILEIRO DE GEOGRAFIA E ESTATÍSTICA (IBGE). Levantamento Sistêmico da Produção Agrícola. Produção anual de banana verde. 2011. Disponível em: <www.ibge.gov.br/home/estatistica/indicadores/agropecuaria/lspa/lspa_201101.pdf>. Acesso em: 17 de maio 2016.

KOLIDA, S.; GIBSON, G. R. Synbiotics in health anda disease. Annual Review of Food Science and Technology, v, 2 p. 373-393, 2011.

LEITE, S. T. Iogurte simbiótico de açaí (Euterp adulis Mart.): caracterização físicoquímica e viabilidade de bactérias lácticas e probióticas. 2015. Dissertação (Mestrado em Ciência e Tecnologia de Alimentos) - Universidade Federal do Espírito Santo. Alegre, Espírito Santo, 2015.

LOPES, D. C. F. Desenvolvimento de Bebida Láctea Adicionada de Ácido Linoléico Conjugado e Ensaio Clínico em Mulheres Obesas, 2010. Dissertação (Mestrado) Faculdade de Farmácia da UFMG, Belo Horizonte, Minas Gerais, 2010. 
MONTANUCI, F. D.; GARCIA, S.; PRUDENCIO, S. H. Caracterização sensorial e aceitação de kefir adoçado integral e desnatado com inulina. Braz. J. Food Techonol, p.70-90, 2010.

MORAES, F.P. Alimentos funcionais e nutracêuticos: definições, legislação e benefícios à saúde. Revista Eletrônica de Farmácia, v. 3, n. 2, 2007.

NOBHAKTI, A. R. et al. Influence of lactulose and hi-maize addition on viability of probiotic microorganisms in freshly made symbiotic fermented milk drink. Milchwissenschaf. v. 64, n. 2, p. 191-193, 2009.

OLIVEIRA, H. S. Comportamento de cultivares de banana (Musa spp) resistentes a doença no processo de micropropagação, 2010. 79 f. Dissertação (Mestrado em Agronomia) - Universidade Federal Rural da Amazônia, Belém, Pará, 2010.

PAQUIN, P. Functional and speciality beverage technology. Boca Raton: CRC Press LLC, 2009.

PERUCHA, V. R. Propriedades funcionais da banana verde: nutrição, saúde e performance. Anuário de alimentos funcionais, edição n. 26, São Paulo, 2005.

PIMENTEL, T. C.; GARCIA, S.; PRUDENCIO, S. Aspectos funcionais de saúde tecnológicos de frutanos tipo inulina. B. CEPPA, Curitiba, v. 30, n. 1, p. 103-118, jan./jun. 2012.

PRUDÊNCIO, E. S. Leites fermentados e suas características. In: $5^{\text {a }}$ SEMANA DE ENSINO, PESQUISA E EXTENSÃO. 5a , 2005, Florianópolis. Anais... Florianópolis: Universidade Federal de Santa Catarina, 2005.

RIBEIRO, M. M. et al. Estudo de mercado de iogurte da cidade de Belo Horizonte/MG. Ceres, v. 57, n. 2, p. 151-156, 2010.

SAAD, S. M. I. Probiótico e prebiótico: estado da arte. Revista Brasileira de Ciências Farmacêuticas, v. 42, n. 1, p.1-12, 2006.

SAAD, S. M. I; CRUZ, A. G.; FARIA, J. A. F. Probióticos e prebióticos em alimentos fundamentos e aplicações tecnológicas. São Paulo: Varella, 2011.

SANTOS, D. T.; VEGGI, P. C.; MEIRELES, M. A. A. Extratition of antioxidant compounds from Jabuticaba (Myrciaria cauliflora) skins: yield, composition and economical evaluation. Journal of Food Engineering, v.101, n. 1, p. 23-31, 2010.

SILVA, N. et al. Manual de métodos de análise microbiológica de alimentos e água. 4. ed. São Paulo: Varela, 632 p. 2010. 
SILVA, R.; VIEIRA, A. Determinação dos parâmetros cinéticos de crescimento de Bacillus coagulans em condições isotérmicas, 2014. 59 f. Monografia (Especialização em Engenharia de Alimentos) - Universidade Federal de Rondônia, Ariquemes, Rondônia, 2014.

SOUZA, C. de. Aplicação do colostro bovino no desenvolvimento de um iogurte simbiótico. 2015. 52 f. Trabalho de Conclusão de Curso. (Curso de Engenharia de Alimentos) - Universidade Tecnológica Federal do Paraná, Medianeira, 2015.

TAMINE, A. Y.; ROBINSON, R. K. Yogur: ciencia y tecnologia. Zaragoza: [s. n.], 1991. $368 \mathrm{p}$.

THAMER, K. G.; PENNA, A. L. B. Caracterização de bebidas lácteas funcionais fermentadas por probióticos e acrescidas de prebiótico. Ciência e Tecnologia de Alimentos, Campinas, ano 26, n. 3, p. 589-595, jul.-set., 2006.

THARMARAJ, N.; SHAH, N. P. Selective, Lactobacillus acidophilus, Bifidocacteria, Lactobacillus casei, Lactobacillus rhamnosus, an Propionibacteria. Journal of Dairy Science, v. 86, p. 2288-2296, 2003.

TRENTO, F. K. H. S. et al. Contagem de bactérias lácticas e probióticas em diferentes formulações de leites fermentados contendo ou não probióticos, após o processo e durante a estocagem. In: CONGRESSO NACIONAL DE LATICÍNIOS., 26º 2009, Juiz de Fora. Anais... Juiz de Fora; UFJF, 2009.

VIDAL, A. M. et al. A ingestão de alimentos funcionais e sua contribuição para a diminuição da incidência de doenças. Caderno de Graduação - Ciências Biológicas e da Saúde - UNIT, v.1, n.1, p.43-52, 2012.

VIEIRA, L. M. et al. Fenólicos totais e capacidade antioxidante in vitro de polpas de frutos tropicais. Revista Brasileira de Fruticultura, v. 33, n. 3, p. 888-897, 2011.

VIEIRA, T. A. Desenvolvimento de sobremessa láctea simbiótica, 2011, 90 f. Dissertação (Mestrado em Engenharia de Alimentos) - Centro Universitário do Instituto de Mauá, São Caetano do Sul, São Paulo, 2011.

ZANDONADI, R. P. Massa de banana verde: uma alternativa para exclusão do glúten. Brasília, 2009. Tese (Doutorado em Ciências da Saúde) - Universidade de Brasília, Brasília, 2009.

ZICKER, M. C. Obtenção e utilização do extrato aquoso de jabuticaba (Myrciaria Jabuticaba (Vell) Berg) em leite fermentado: caracterização físico-química e sensorial, 2011. Dissertação (Mestrado em Ciência de Alimentos) - Faculdade de Farmácia da UFMG, Belo Horizonte, MG, 2011. 


\title{
BIOMASS ADDITION OF INTERFERENCE AND FLOUR GREEN BANANA (MUSA SPP.) AND FLOUR JABUTICABA BARK (MYRCIARIA CAULIFLORA) THE MULTIPLICATION PROBIOTIC BACTERIA MILK IN GROWING LIGHT
}

\begin{abstract}
The demand for foods that have beneficial effects has encouraged industries to develop functional products. In this context, the objective in the present study was to evaluate the interference of adding biomass and green banana flour and jabuticaba bark flour in maintaining probiotic culture grown in light milk. 4 formulations were prepared called F1 (control), F2 (10\% biomass), F3 (5\% banana flour) and F4 (5\% jabuticaba pulp and $0.8 \%$ jabuticaba bark flour). The samples were subjected to counting of total lactic acid bacteria at 0, 10, 20 and 30 days. It was used mixed probiotic Lactobacillus acidophilus, Bifidobacterium sp. and Streptococcus salivarius subsp. thermophilus. The count of total lactic acid bacteria has met the requirements of legislation and the addition of biomass, green banana flour and jabuticaba bark flour influence the viability of the probiotic culture during the storage period.
\end{abstract}

Keyword: Fermented milk. Functional food. Fiber food.

Submetido em: 24/06/2016

Aprovado em: 15/06/2016

Publicado em: 06/10/2017 